\title{
The Productive Efficiency of the Health Care Sector of China ${ }^{+}$
}

\author{
Ying Chu $\mathrm{Ng}^{*}$
}

\begin{abstract}
Based on four years of province-level health care data, this paper analyzes the productive efficiency of China's health care sector in the post reform period. Data envelopment analysis is used to compute efficiency measures, which indicate that there was still room for improvement in the technical efficiency of the health care sector in China between 2002 and 2005. This is particularly the case in the coastal provinces. According to the computed Malmquist index and its decomposition components, China's health care sector suffers from productivity decline, especially for the coastal provinces. Nevertheless, there has been technological improvement across all provinces.
\end{abstract}

Keywords: efficiency; Malmquist index; health care; China

JEL Classifications: L1; D4

\section{INTRODUCTION}

Economic reforms have been implemented in several sectors of China's economy. The success of rural reforms and enterprise reforms has been well documented, and China has been enjoying economic growth at an annual rate of 7.9 percent since the 1980s. Regardless of this tremendous growth, the Chinese government has not put substantial resources into the health care sector. The nation's total expenditures on health care (from all sources) were 3.07 percent of GDP in 1985 and 3.86 percent in 1995 (Liu, 2004). By 2002, as reported in the World Health Report (2005), the figure was 5.8 percent, and 5.6 percent in 2004 (Hougaard, Osterdal, and Yu, 2008). Although these figures are higher than those for other developing economies in Asia, they are rather out of line with the economic growth China has been enjoying.

Health care reform in China started in parallel with the enterprise reforms begun in 1985 . The government successfully reduced its financial burden in the health care sector from more than 25 percent of total health expenditures in the early 1980s (Zhang and Kanbur, 2005) to 23 percent in 1991. By 2000, only 14 percent of total expenditures on health were funded by the government (Liu, 2004, Liu et al., 2006). In terms of government funding as a share of various health funding sources, it was 60 percent in 1989 and fell to 42 percent in 2002 (Blumenthal and Hsiao, 2005). At the same time, greater autonomy was granted to hospitals and other health institutions at the provincial level. With the substantial budget cut in health care, Liu and Mills (2002) have commented that health care institutions became revenue maximizers, and economic inefficiency in health care provision was a likely outcome. Based on a comprehensive review of the health care system in China, Eggleston et al. (2008) asserted that the Chinese health care delivery system was subject to: (1) inefficiency, (2) provision of unnecessary care, (3) poor

\footnotetext{
${ }^{+}$The author acknowledges with gratitude the generous support of the Research Committee, Hong Kong Baptist University for the project (FRG/06-07/I-25), without which the timely production of the current publication would not have been feasible. The comments received at the Asia-Pacific Productivity Conference 2008 (APPC, 2008), Taipei, Taiwan, June 17-19, 2008, also are appreciated.

* The author is an Associate Professor of Economics, Hong Kong Baptist University, Kowloon Tong, Kowloon, Hong Kong, China. E-mail: ycng@hkbu.edu.hk.

(C) Southern Regional Science Association 2010.

ISSN 1553-0892

SRSA, 1601 University Avenue, PO Box 6025, Morgantown, West Virginia 26506-6025, USA.
} 
quality, (4) excessive reliance on drugs and high-tech care, and (5) insufficient focus on public health.

Another consequence of the health care reform has been the provider-induced overconsumption of drugs and services ( $\mathrm{Gu}$ and Zhang, 2006) and the overuse of high-technology diagnosis and treatment (Tang and Meng, 2004). Figures from the Ministry of Health indicate that the income from medical services as a percentage of the total income of health institutions grew from 18.9 percent in 1980 to 40.2 percent in 2000 (Tang and Meng, 2004). For drugs, the percentage was 37.7 percent in 1980, which increased to 43.1 percent in 1990 and was 47.1 percent by 2000. Blomqvist and Qian (2008), Blumenthal and Hsiao (2005), and Meng et al. (2005) reported that nearly half of Chinese health care spending was devoted to drugs. Accordingly, it is suspected that inefficiency in health care provision exists in China, but no prior work has been done on the issue. This study is an attempt to fill the gap by examining the performance of the health care sector in China.

The assertion that economic reforms have induced growth imbalances among China's regions has been well documented. In health care, autonomy in decision making and financing has combined with the differentials in the pace of economic development to lead to variations in health care performance by region. Using provincial level data, the productive efficiency of the health care sector by province can be assessed using data envelopment analysis (DEA), thus allowing general regional performance to be outlined. To enhance the understanding of the issue, one or more provinces can then be identified to serve as "role models" for other provinces to follow.

Efficiency estimation provides a measure of how the health care sector performs compared to the production frontier given the technology. An improvement in efficiency across time leads to an increase in productivity. Over time, changes in technology shift the production frontier and thus productivity growth is observed. The health care sector constantly experiences technological advancement. The computation of Malmquist index (change in productivity over time) and its decomposition allows us to shed some light on the productivity effect of the adoption of high-tech treatments on the health care sector as well as that of its efficiency change.

The rest of the paper is organized as follows. The next section describes prior research on productive efficiency in health care. It is followed by an explanation of this study's data and methodology, and the presentation of the empirical results. The last two sections are discussion and conclusion, respectively.

\section{PRIOR RESEARCH ON HEALTH CARE SECTOR PERFORMANCE}

The productive efficiency of health care can be assessed at the hospital level, the health center level, the provincial level, or even the country level. Most previous country-level studies have analyzed countries in the Organisation for Economic Co-operation and Development (OECD). Puig-Junoy (1998) compared the technical efficiency of health care in OECD countries between 1960 and 1990. He found that overall, technical efficiency improved over time, mostly as a result of improved scale efficiency. The OECD countries consistently improved in pure technical efficiency (estimated efficiency score no less than 0.91). Using different outputs, a later DEA study computed both input-oriented and output-oriented variable returns to scale in 27 OECD countries (Retzlaff-Roberts, Chang, and Robin, 2004). The results for 1998 indicated that 13 of the 27 countries were efficient regardless of which approach was adopted. In absolute 
terms, the output-oriented approach suggested that infant mortality could be improved by 14.5 percent and life expectancy by 2.1 percent, on average. However, adopting the input-oriented approach, 14.0 percent of inputs could have been saved if infant mortality were the target output, while 21.0 percent of inputs could have been saved if life expectancy were the target output.

Studying 1996 provincial hospital data from Turkey, Sahin, and Ozcan (2000) found that 44 of the 80 provinces were inefficient, with an average efficiency score of 0.781 . For the nation as a whole, about 13 percent less input was theoretically needed to produce the 1996 output level. Giuffrida and Gravelle (2001) examined the performance of British Family Health Service Authorities (FHSAs) in the periods 1993-1994 and 1994-1995. They applied various methods and showed that the average efficiencies computed using DEA were similar to those resulting from the regression-based methods and were within the ranges of stochastic frontier models. In a study of 133 health care centers in Greece in 1999, input-based DEA indicated that mediumsized centers were relatively more efficient than larger and smaller units (Zavras et al., 2002). With slightly different input and output mixes, Kontodimopoulos, Nanos, and Niakas (2006) estimated the efficiency scores of 17 hospital health centers in Greece in 2003. The overall average efficiency estimates were quite similar to those of Zavras et al. (2002), and the results suggested that the centers required only 73 percent of the inputs currently applied to produce the existing levels of outputs.

In Asia, Hu and Huang (2004) produced the first study of medical centers and regional hospitals in Taiwan. Data on 80 centers in 2001 were collected and subjected to input-based DEA. The 5-input/4-output estimation results revealed high pure technical efficiency (0.927) as well as scale efficiency $(0.965)$, resulting in an overall technical efficiency of 0.895 for the whole sample. On the other hand, 32 public health centers in Kenya were found to be quite inefficient (Kirigia et al. 2004). Their average technical efficiency score was 0.65 while the average scale efficiency score was 0.70 .

Using a sample of 91 general and teaching hospitals in Greece in 1992, Giokas (2001) found that general hospitals were less efficient than teaching hospitals. In the case of Taiwan, an analysis of 6 central government-owned hospitals revealed that there was a decrease in efficiency between 1990 and 1991. With the implementation of their National Health Insurance program, an improvement in efficiency was found for the period 1992-1994. Another hospital level study focused on regional differences and time trends among 65 hospitals in the Ukraine. Pilyavsk et al. (2006) took advantage of the political differences between east and west Ukraine in examining how regional development affects the performance of hospitals. Between 1997 and 2001, the annual variable returns to scale output-based efficiency estimates indicated that hospitals located in the east did not show any changes in efficiency, but there was a fall in efficiency by 13.7 percent for hospitals in the west during the period. Brown and Pagán (2006) use input-oriented DEA to address the relationship between managed care and hospital scale efficiency in the US between 1992 and 1996. A cross-country review on DEA-based hospital efficiency studies can be found in O'Neill et al. (2008).

A literature review on productive efficiency in health care services by Hollingsworth (2003) has shown that there have been many such studies, but that only a handful has addressed productivity growth. At the country level, Färe et al. (1997) and Hollingsworth and Wildman (2003) are among the few examples. Based on the different types of outputs, Färe's group estimated intermediate and outcomes models for 19 OECD countries between 1974 and 1989. The output-based Malmquist index they computed demonstrated that most countries recorded a 
decline in productivity growth in terms of the intermediate model, but that there was dramatic productivity growth in terms of the outcome models. Hollingsworth and Wildman (2003) used World Health Organization data for 140 countries to show that there was a productivity regression between 1993 and 1997. Although there was an improvement in efficiency over time, a deceleration in technological change was found, causing a regression in overall productivity growth. An analysis of productivity growth in health centers has been published by Giuffrida (1999). His variable returns to scale Malmquist index calculation for 90 FHSAs in England showed that there was acceleration in efficiency gains as well as in technological progress between 1990-1991 and 1994-1995.

\section{DATA AND APPROACH}

\subsection{Data}

No secondary data could be found readily available and in a format suitable for analysis. Raw input and output data on health care in China were extracted from the China Health Care Statistical Yearbooks. Because of incomparable medical practices in the Tibet and Xinjiang autonomous regions, the analysis used only the data from the other 29 provinces and municipalities (provinces hereafter) for the period 2002-2005. Based on the official classification, Beijing, Tianjin, Hebei, Liaoning, Shanghai, Jiangsu, Zhejiang, Fujian, Shandong, Guangdong, Guangxi and Hainan were treated as the coastal region, and the other 17 provinces were termed the inland (non-coastal) region.

The Statistical Yearbooks provide health care input data on the number of doctors, the number of nurses and the number of other medical staff (the labor inputs); and on the number of beds (a capital input). Health care production is complicated ${ }^{1}$, so both intermediate model and outcomes model approaches were adopted (see Färe et al., 1997) to measure output. For the intermediate model approach, the number of hospital inpatient stays and the number of hospital outpatient visits were the two outputs studied. The mortality rate has been used as output in the outcomes model approach (Färe et al., 1997; Retzlaff-Roberts, Chang, and Robin, 2004; Sahin and Ozcan, 2000). However, due to interpretation difficulty and the problem of using ratios in the DEA estimation, ${ }^{2}$ the present study makes use of the provincial mortality rate to construct the provincial population net of the number of deaths. ${ }^{3}$

\subsection{Approach}

Let $U_{j}=\left(u_{1 j}, u_{2 j}, \ldots, u_{M j}\right)$ and $X_{j}=\left(x_{1 j}, x_{2 j}, \ldots, x_{N j}\right)$ be the observed output and input vectors of the jth province's health care sector in a sample of $J$ provinces. Assuming strong disposability of inputs and outputs, the overall Farrell input-oriented technical measure (TE) can be computed using a typical nonparametric frontier,

$$
\begin{array}{ll}
T E_{j}=\min \lambda \\
\text { subject to } & \sum_{i} z_{i} u_{m i} \geq u_{m j} \quad(m=1, \ldots, M) \\
& \sum_{i} z_{i} x_{n i} \leq \lambda_{j} x_{n j} \quad(n=1, \ldots, N)
\end{array}
$$

\footnotetext{
${ }^{1}$ The published data do not allow the analysis to take into account issues associated with case mix or/and quality of services.

${ }^{2}$ Please refer to Emrouznejad and Amin (2008) and Hollingsworth and Smith (2003).

${ }^{3}$ Net population equals ( 1 minus mortality rate) times the population size.
} 


$$
\sum_{i} z_{i}=1
$$

The technology behind this problem exhibits variable returns to scale and strongly disposable inputs. The main assumption is that the technology set is convex. If the last constraint in (1) is removed, constant returns to scale are assumed in the DEA. Any differences in the efficiencies estimated assuming variable and constant returns to scale then imply scale inefficiencies. Formally, scale efficiency ${ }^{4}$ is calculated as the ratio of the constant returns to scale technical efficiency score to the variable returns to scale technical efficiency score. The variable returns to scale technical efficiency score can then be decomposed into scale efficiency and pure technical efficiency.

Addressing the productivity change issue, the Malmquist index assumes that for each period $t=1,2, \ldots, T$, production units transform inputs $\left(x^{t}\right)$ into outputs $\left(u^{t}\right)$ according to production technology $\mathrm{S}^{\mathrm{t}}$. The index can be expressed using various distance functions, such as $D_{0}^{t}\left(u^{t}, x^{t}\right)$, (Shephard, 1970; Färe, 1988). Caves, Christenson, and Diewert (1982) defined the input-based Malmquist index in period $t$ as

$$
M_{o}^{t}=\frac{D_{o}^{t}\left(u^{t+1}, x^{t+1}\right)}{D_{o}^{t}\left(u^{t}, x^{t}\right)} .
$$

Alternatively, for period $t+1$,

$$
M_{o}^{t+1}=\frac{D_{o}^{t+1}\left(u^{t+1}, x^{t+1}\right)}{D_{o}^{t+1}\left(u^{t}, x^{t}\right)}
$$

Based on the work of Färe, Grosskopf, and Weber (1989) and Färe et al. (1992), the Malmquist index used in this study was the geometric mean of the above two indices. That is,

$$
M_{o}\left(u^{t+1}, x^{t+1}, u^{t}, x^{t}\right)=\left[\left(\frac{D_{o}^{t}\left(u^{t+1}, x^{t+1}\right)}{D_{o}^{t}\left(u^{t}, x^{t}\right)}\right)\left(\frac{D_{o}^{t+1}\left(u^{t+1}, x^{t+1}\right)}{D_{o}^{t+1}\left(u^{t}, x^{t}\right)}\right)\right]^{1 / 2} .
$$

This index avoids arbitrarily selecting one of the time periods as the reference point. This index can then be decomposed into two components:

$$
\begin{aligned}
& M_{o}\left(u^{t+1}, x^{t+1}, u^{t}, x^{t}\right)= \\
& \frac{D_{o}^{t+1}\left(u^{t+1}, x^{t+1}\right)}{D_{o}^{t}\left(u^{t}, x^{t}\right)}\left[\left(\frac{D_{o}^{t}\left(u^{t+1}, x^{t+1}\right)}{D_{o}^{t+1}\left(u^{t+1}, x^{t+1}\right)}\right)\left(\frac{D_{o}^{t}\left(u^{t}, x^{t}\right)}{D_{o}^{t+1}\left(u^{t}, x^{t}\right)}\right)\right]^{1 / 2}
\end{aligned}
$$

The first component (the term in front of the square brackets) measures efficiency change, or how the position of the observed production unit has changed relative to the production frontier between time points $t$ and $t+1$. That is, productivity change across time that is attributed to efficiency change across time. The second component (the term in the square brackets) measures technical change, or how the production frontier shifted between the periods. In other words, any

\footnotetext{
${ }^{4}$ The meaning of scale efficiency is not clear for studies at the aggregate level and thus the present study focuses on the two technical efficiency terms.
} 
change in technology can bring about change in productivity. The corresponding linear programming problems associated with the distance functions expressed in (5) can be found in Färe et al. (1994). An index value greater than one means deterioration in productivity growth, while a value less than one implies growth in productivity. With the limited data available for China, one Malmquist index was computed in this study for each adjacent period and the period 2002-2005.

Both the efficiency estimation and the computation of the Malmquist index are done at the provincial level. That is, the production frontier involved in the DEA estimation is constructed using the data from the 29 provinces. In presenting the results, statistics or figures represent the regional information according to the classification of coastal and non-coastal described earlier.

\section{EMPIRICAL RESULTS}

Between 2002 and 2005, health care inputs grew continuously across all regions (Table 1, panel A). Inland provinces devoted fewer resources (staff and beds) to the health care sector. Moreover, their use of health care inputs (2002-2005) did not grow as in coastal provinces. For example, the percentage increase in the number of doctors in coastal provinces ( 7.1 percent) was twice that in the inland provinces ( 3.3 percent). There were substantial increases in the number of other health care staff, but the increase was 100 percent on the coast and only 78.8 percent in the inland provinces.

In terms of outcomes, the two modeling approaches painted similar pictures. The intermediate model approach showed that the coastal provinces had more hospital outpatient visits and inpatient stays (Table 1, panel B). The percentage increase in outpatient visits was nearly three times greater in the coastal provinces than inland (15.9 percent vs. 5.7 percent) during the period. From the viewpoint of the outcomes model, the improvement in the mortality rate at the provincial level was slightly better for the coastal provinces between 2002 and 2005. Translating into the population figure net of the number of deaths, the figures in square brackets revealed similar picture of the mortality rate with the exception of 2005 for non-coastal provinces.

Although provinces in the coastal region devoted more inputs to the health care sector, there is no evidence that these provinces were efficient in health care provision. There is at least anecdotal evidence that they offer a higher level of health care services, which has lead to improvements in the mortality rates. Still, evidence suggests that if they had been technically efficient, these provinces should have required 75 percent to 89 percent of the inputs used. The table also shows that coastal provinces were, overall, less technically efficient (a smaller value of the score) than their inland counterparts, even though over time there was an improvement in overall technical efficiency in both regions. The improvement in overall technical efficiency in the inland provinces was slightly greater (from 0.82 to 0.89 versus from 0.84 to 0.87 ).

The inefficiency mainly originated from pure technical inefficiency in both regions. As with the overall technical inefficiency, pure technical inefficiency was much more serious along the coast than inland in all years. Specifically, about 82 percent to 92 percent of the inputs actually used were required to produce the observed amount of hospital inpatient and outpatient services for the inland provinces if they were pure technically efficient (Table 2). These 
percentages ranged from 78 percent to 89 percent for provinces in the coastal area. As indicated in Table 2, scale inefficiency did not seem to be a problem for provinces in either region.

TABLE 1. Sample Statistics of Study Variables by Year and Region

\begin{tabular}{|c|c|c|c|c|}
\hline Panel A (Inputs) & 2002 & 2003 & 2004 & 2005 \\
\hline \multicolumn{5}{|l|}{ Coastal $(N=12)$} \\
\hline Number of doctors & $\begin{array}{r}68,715.17 \\
(36,241.70)\end{array}$ & $\begin{array}{r}69,565.25 \\
(37,612.45)\end{array}$ & $\begin{array}{r}71,765.67 \\
(39,183.81)\end{array}$ & $\begin{array}{r}73,565.33 \\
(40,516.03)\end{array}$ \\
\hline Number of nurses & $\begin{array}{r}49,568.17 \\
(25,392.20)\end{array}$ & $\begin{array}{r}50,330.25 \\
(25,834.13)\end{array}$ & $\begin{array}{r}52,692.67 \\
(27,221.89)\end{array}$ & $\begin{array}{r}54,698.50 \\
(28,427.88)\end{array}$ \\
\hline Number of other health staff & $\begin{array}{r}20,664.08 \\
(13,256.21)\end{array}$ & $\begin{array}{r}42,122.92 \\
(26,309.99)\end{array}$ & $\begin{array}{r}43,108.67 \\
(26,648.49)\end{array}$ & $\begin{array}{r}43,409.42 \\
(26,854.41)\end{array}$ \\
\hline Number of beds & $\begin{array}{l}11,7982.58 \\
(63,738.43)\end{array}$ & $\begin{array}{l}118,661.58 \\
(63,564.70)\end{array}$ & $\begin{array}{l}123,750.33 \\
(67,424.16)\end{array}$ & $\begin{array}{l}128,845.58 \\
(71,837.34)\end{array}$ \\
\hline \multicolumn{5}{|l|}{ Inland ( $N=17)$} \\
\hline Number of doctors & $\begin{array}{r}57,481.47 \\
(28,917.73)\end{array}$ & $\begin{array}{r}58,143.41 \\
(29,551.18)\end{array}$ & $\begin{array}{r}58,689.53 \\
(29,760.04)\end{array}$ & $\begin{array}{r}59,380.53 \\
(29,913.03)\end{array}$ \\
\hline Number of nurses & $\begin{array}{r}36,586.47 \\
(18,573.67)\end{array}$ & $\begin{array}{r}37,056.35 \\
(18,893.34)\end{array}$ & $\begin{array}{r}37,844.94 \\
(19,535.03)\end{array}$ & $\begin{array}{r}38,862.00 \\
(20,119.88)\end{array}$ \\
\hline Number of other health staff & $\begin{array}{r}20,524.29 \\
(13,473.87)\end{array}$ & $\begin{array}{r}37,635.18 \\
(23,977.18)\end{array}$ & $\begin{array}{r}37,209.53 \\
(23,651.16)\end{array}$ & $\begin{array}{r}36,694.47 \\
(23,594.42)\end{array}$ \\
\hline Number of beds & $\begin{array}{r}96,860.88 \\
(50,547.06)\end{array}$ & $\begin{array}{r}97,707.00 \\
(51,740.39)\end{array}$ & $\begin{array}{r}99,935.47 \\
(52,925.81)\end{array}$ & $\begin{array}{l}10,2049.12 \\
(54,087.71)\end{array}$ \\
\hline Panel B (Outputs) & 2002 & 2003 & 2004 & 2005 \\
\hline \multicolumn{5}{|l|}{ Coastal (N=12) } \\
\hline $\begin{array}{l}\text { Number of hospital outpatient } \\
\text { visits }\end{array}$ & $\begin{array}{r}57,641,384.25 \\
(35,031,599.93)\end{array}$ & $\begin{array}{r}56,251,409.83 \\
(37,050,693.10)\end{array}$ & $\begin{array}{c}61,931,038.17 \\
(41,310,287.87)(\end{array}$ & $\begin{array}{r}66,809,817.92 \\
(45,555,526.59)\end{array}$ \\
\hline $\begin{array}{l}\text { Number of hospital inpatient } \\
\text { stays }\end{array}$ & $\begin{array}{l}1,611,727.50 \\
(939,165.32)\end{array}$ & $\begin{array}{r}1,665,293.67 \\
(1,009,950.01)\end{array}$ & $\begin{array}{r}1,892,937.17 \\
(1,144,488.90)\end{array}$ & $\begin{array}{r}2,075,643.17 \\
(1,260,164.93)\end{array}$ \\
\hline $\begin{array}{l}\text { Mortality rate (figures in } \\
\text { square bracket are in } \\
\text { thousands) }\end{array}$ & $\begin{array}{r}6.04 \\
(0.50) \\
{[1,704.22]}\end{array}$ & $\begin{array}{r}6.05 \\
(0.57) \\
{[1,690.91]}\end{array}$ & $\begin{array}{r}5.94 \\
(0.54) \\
{[1,781.85]}\end{array}$ & $\begin{array}{r}5.97 \\
(0.63) \\
{[1,826.50]}\end{array}$ \\
\hline \multicolumn{5}{|l|}{ Inland $(N=17)$} \\
\hline $\begin{array}{l}\text { Number of hospital outpatient } \\
\text { visits }\end{array}$ & $\begin{array}{r}30,947,471.35 \\
(17,075,842.17)\end{array}$ & $\begin{array}{r}30,000,006.35 \\
(17,098,796.53)\end{array}$ & $\begin{array}{c}31,290,808.41 \\
(17,701,900.45)\end{array}$ & $\begin{array}{r}32,711,532.53 \\
(19,088,343.73)\end{array}$ \\
\hline $\begin{array}{l}\text { Number of hospital inpatient } \\
\text { stays }\end{array}$ & $\begin{array}{l}1,153,300.18 \\
(623,390.43)\end{array}$ & $\begin{array}{l}1,196,601.82 \\
(664,965.93)\end{array}$ & $\begin{array}{l}1,332,260.71 \\
(740,207.48)\end{array}$ & $\begin{array}{l}1,454,194.00 \\
(825,504.13)\end{array}$ \\
\hline $\begin{array}{l}\text { Mortality rate (figures in } \\
\text { square bracket are in } \\
\text { thousands) }\end{array}$ & $\begin{array}{r}6.13 \\
(0.68) \\
{[1,599.92]} \\
\end{array}$ & $\begin{array}{r}6.16 \\
(0.67) \\
{[1,610.74]} \\
\end{array}$ & $\begin{array}{r}6.11 \\
(0.52) \\
{[1,633.78]} \\
\end{array}$ & $\begin{array}{r}6.11 \\
(0.63) \\
{[1,562.89]} \\
\end{array}$ \\
\hline
\end{tabular}

Southern Regional Science Association 2010. 
Adopting the outcomes model approach, the yearly productive efficiency figures depict results similar to those from the intermediate model approach with a few exceptions. Notably, there is a relative lower efficiency estimate using the outcomes model approach. The estimated scale efficiency is relatively lower in this approach, although pure technical inefficiency remained the driving force for overall technical inefficiency for provinces in either region. As shown in Table 3, with the improvement over the years, only about 70 percent of the actual inputs would have been technically efficient for the sector of the coastal provinces. For the noncoastal provinces, on average, about 80 percent of the existing inputs would allow their health care sector to be technically efficient.

TABLE 2. Efficiency Measures and Their Decomposition for Hospital Services as the Output Measure by Region, 2002-2005

\begin{tabular}{lrrrr}
\hline \hline Coastal & $\mathbf{2 0 0 2}$ & $\mathbf{2 0 0 3}$ & $\mathbf{2 0 0 4}$ & $\mathbf{2 0 0 5}$ \\
\hline Overall technical efficiency & 0.8367 & 0.7437 & 0.8434 & 0.8669 \\
Scale efficiency & 0.9760 & 0.9486 & 0.9662 & 0.9722 \\
Pure technical efficiency & 0.8572 & 0.7840 & 0.8729 & 0.8918 \\
$N$ & 12 & 12 & 12 & 12 \\
& & & & \\
Inland & $\mathbf{2 0 0 2}$ & $\mathbf{2 0 0 3}$ & $\mathbf{2 0 0 4}$ & $\mathbf{2 0 0 5}$ \\
Overall technical efficiency & 0.8174 & 0.7584 & 0.8714 & 0.8866 \\
Scale efficiency & 0.9355 & 0.9216 & 0.9766 & 0.9633 \\
Pure technical efficiency & 0.8737 & 0.8230 & 0.8923 & 0.9204 \\
$N$ & 17 & 17 & 17 & 17 \\
\hline \hline
\end{tabular}

TABLE 3. Efficiency Measures and Their Decomposition for the Transformed Mortality Rate as the Output Measure by Region, 2002-2005

\begin{tabular}{lrrrr}
\hline \hline Coastal & $\mathbf{2 0 0 2}$ & $\mathbf{2 0 0 3}$ & $\mathbf{2 0 0 4}$ & $\mathbf{2 0 0 5}$ \\
\hline Overall technical efficiency & 0.6384 & 0.5994 & 0.6033 & 0.6911 \\
Scale efficiency & 0.9537 & 0.9330 & 0.9242 & 0.9708 \\
$\begin{array}{l}\text { Pure technical } \\
\text { efficiency }\end{array}$ & 0.6694 & 0.6425 & 0.6528 & 0.7119 \\
$N$ & 12 & 12 & 12 & 12 \\
\hline Inland & $\mathbf{2 0 0 2}$ & $\mathbf{2 0 0 3}$ & $\mathbf{2 0 0 4}$ & $\mathbf{2 0 0 5}$ \\
\hline $\begin{array}{l}\text { Overall technical } \\
\text { efficiency }\end{array}$ & 0.7208 & 0.7171 & 0.7053 & 0.8019 \\
$\begin{array}{l}\text { Scale efficiency } \\
\text { Pure technical }\end{array}$ & 0.9449 & 0.9284 & 0.9025 & 0.9460 \\
efficiency & 0.7628 & 0.7724 & 0.7815 & 0.8476 \\
$N$ & 17 & 17 & 17 & 17 \\
\hline \hline
\end{tabular}


TABLE 4. Malmquist Index and Its Decomposition for Hospital Services as the Output Measure by Region, 2002-2005

\begin{tabular}{lrrrr}
\hline Coastal & $\mathbf{2 0 0 2 - 2 0 0 5}$ & $\mathbf{2 0 0 2 - 2 0 0 3}$ & $\mathbf{2 0 0 3 - 2 0 0 4}$ & $\mathbf{2 0 0 4 - 2 0 0 5}$ \\
\hline Malmquist Index & 1.1307 & 1.3796 & 0.9211 & 0.9346 \\
Technological change & 1.1467 & 1.2608 & 1.0048 & 0.9508 \\
Change in efficiency & 0.9860 & 1.0943 & 0.9167 & 0.9829 \\
Change in scale efficiency & 1.0141 & 1.0352 & 0.9815 & 0.9980 \\
Change in technical efficiency & 0.9723 & 1.0571 & 0.9340 & 0.9848 \\
$N$ & 12 & 12 & 12 & 12 \\
Inland & $\mathbf{2 0 0 2 - 2 0 0 5}$ & $\mathbf{2 0 0 2 - 2 0 0 3}$ & $\mathbf{2 0 0 3 - 2 0 0 4}$ & $\mathbf{2 0 0 4 - 2 0 0 5}$ \\
Malmquist Index & 0.9853 & 1.2350 & 0.9047 & 0.9458 \\
Technological change & 1.0851 & 1.1237 & 1.0716 & 0.9693 \\
Change in efficiency & 0.9080 & 1.0990 & 0.8468 & 0.9758 \\
$\quad$ Change in scale efficiency & 0.9643 & 1.0107 & 0.9439 & 1.0108 \\
$\quad$ Change in technical efficiency & 0.9417 & 1.0873 & 0.8971 & 0.9654 \\
$N$ & 17 & 17 & 17 & 17 \\
\hline \hline
\end{tabular}

Productivity change was estimated for three annual periods as well as for the full range of four years. As with the efficiency measures, hospital services as output and net population figures as output were considered. Table 4 reveals an interesting pattern of productivity change by region for hospital services used as output in the Malmquist index computation. As a whole, non-coastal provinces experienced productivity regression (Malmquist index values greater than one) between 2002 and 2003 but productivity growth (Malmquist index of values less than one) in the two subsequent years. Still, productivity growth across the full 2002-2005 period was observed for provinces in the non-coastal areas. In contrast, the opposite situation was observed for provinces along the coast. Although productivity growth was observed between 2003 and 2005, the productivity regression in 2002-2003 was not offset by the improvement in subsequent years, resulting in an overall productivity regression between 2002 and 2005. The decomposition of the Malmquist index indicates that any productivity growth in hospital services provision of provinces regardless of their geographic location originated from efficiency change (a value of less than one shown in Table 4), which outweighed the technological regression. Between the subcomponents of the change in efficiency, the role of the change in technical efficiency seemed to play a dominant role in enhancing productivity change. This observation holds for both regions. In sum, over time, the provision of hospital services in the inland provinces outperformed that along the coast.

Turning to the productivity growth analysis using the transformed provincial mortality rate as the output measure, Table 5 reveals that both regions suffered from productivity regression in health care provision with the exception of the period 2003-2004. Nevertheless, for the entire study period (2002-2005), productivity regression was found with particular severity in the coastal region. For provinces in the inland region, change in technology and efficiency played equal roles in determining the productivity change between 2002 and 2004. However, 
TABLE 5. Malmquist Index and Its Decomposition for the Transformed Mortality Rate as the Output Measure by Region, 2002-2005

\begin{tabular}{lrrrr}
\hline \hline Coastal & $\mathbf{2 0 0 2 - 2 0 0 5}$ & $\mathbf{2 0 0 2 - 2 0 0 3}$ & $\mathbf{2 0 0 3 - 2 0 0 4}$ & $\mathbf{2 0 0 4 - 2 0 0 5}$ \\
\hline Malmquist Index & 1.4852 & 1.5632 & 0.9913 & 1.0166 \\
Technological change & 1.5324 & 1.5093 & 0.9618 & 1.1197 \\
Change in efficiency & 0.9692 & 1.0375 & 1.0307 & 0.9079 \\
Change in scale efficiency & 1.0019 & 1.0178 & 1.0277 & 0.9579 \\
Change in technical efficiency & 0.9674 & 1.0176 & 1.0029 & 0.9479 \\
$N$ & 12 & 12 & 12 & 12 \\
Inland & $\mathbf{2 0 0 2 - 2 0 0 5}$ & $\mathbf{2 0 0 2 - 2 0 0 3}$ & $\mathbf{2 0 0 3 - 2 0 0 4}$ & $\mathbf{2 0 0 4 - 2 0 0 5}$ \\
Malmquist Index & 1.3240 & 1.4508 & 0.9813 & 1.0385 \\
Technological change & 1.5238 & 1.4152 & 0.9904 & 1.2140 \\
Change in efficiency & 0.8688 & 1.4152 & 0.9908 & 0.8555 \\
$\quad$ Change in scale efficiency & 0.9849 & 1.0251 & 1.0158 & 0.9498 \\
$\quad$ Change in technical efficiency & 0.8820 & 1.0209 & 0.9753 & 0.9007 \\
$N$ & 17 & 17 & 17 & 17 \\
\hline \hline
\end{tabular}

change in efficiency became dominant by the period 2004-2005. In contrast, technological change shaped the productivity change in coastal provinces for the study period. Another observation is that both change in technical efficiency and change in scale efficiency contributed equally in efficiency change across time for all provinces regardless of their geographic location.

\section{DISCUSSION}

The yearly efficiency scores presented in Tables 2 and 3 indicate the differences in efficiency measures using different outcomes. One possible explanation is the malpractice commonly found in Chinese health care during the health care reform period. Health care institutions such as hospitals, required to balance their budgets with limited financial support from the government, overuse high-tech treatments and overprescribe drugs as two ways of generating a stable income. All these unnecessary services and drugs may not improve the health status of the general public efficiently. At the same time, such practices may prevent the poor from seeking proper health care due to the anticipated expense. Accordingly, it is not surprising that provinces performed reasonably well from the perspective of hospital services provision and yet had relatively low efficiency scores when the transformed mortality rate was used as the outcome measure in the performance assessment.

An implication of the differences in efficiency estimated using different outcomes is that any policy based on efficiency estimates has to be applied with caution. The results presented in Tables 2 and 3 provide a good example of the differences in efficiency estimates which result if different outcome measures are used in the analysis. The study by Färe et al. (1997) provides another example. To avoid any potential bias in drawing conclusions, alternative outcomes should be tested whenever possible. 
The aggregate results by region indicate that, in general, health care sectors in the inland region performed better than those in the coastal region. However, among the best performers, over 70 percent of them are in the coastal region, such as Shanghai, Guangdong, Fujian, Zhejiang, and Shandong. Economic development may have induced more efficient ways of producing or managing, since more market-oriented provinces in the coastal region experienced noticeably better performance in health care provision. As a result, changes in efficiency among provinces in the coastal region were more diverse than they were among inland provinces, resulting in an overall lower average regional efficiency score. Promotion of market reform in general would enhance performance as a whole.

Turning to the productivity growth analysis, given the common practice of adopting hightech treatments it is surprising to find that there is, in general, technological regression in the health care sector of all provinces. It is probably due to the "high-tech race" across provinces that narrows the relative performance (particularly for the case of the mortality rate model) across provinces or minimizes the number of extreme outstanding performers (provincial health care sectors). The production frontier constructed can be compressed, resulting in a decline in productivity growth over time whereas an improvement in efficiency change is observed.

\section{CONCLUSION}

The four years of provincial data show a continuous increase in resources in the health care sector of the coastal provinces. These provinces, on average, were found to be less technically efficient than their non-coastal counterparts. Regardless of which outcome measure was used, the estimated yearly efficiency scores and their decomposition highlighted pure technical inefficiency as the main source of inefficiency. This conclusion holds for provinces in both regions. The geometric mean efficiency scores only provide an average efficiency assessment. Accordingly, provinces in the inland region generally outperformed those on the coast.

In contrast to the improvement in the yearly efficiency estimates, China generally suffered from productivity deterioration in health care provision between 2002 and 2005. This is particularly the case of provinces in the coastal region. One encouraging fact is that there was a technological improvement by 2004-2005 for the provision of health care regardless of region. With continuous improvement in efficiency over the years, there is hope that there will be productivity growth in the years to come.

\section{REFERENCES}

Blomqvist, Áke and Jiwei Qian. (2008) "Health System Reform in China: An Assessment of Recent Trends," Singapore Economics Review, 53, 5-26.

Blumenthal, David and William Hsiao. (2005) "Privatization and its Discounts-The Evolving Chinese Health Care System," The New England Journal of Medicine, 353, 1165-1170.

Brown, H. Shelton III and Jośe A. Pagán. (2006) "Managed Care and the Scale Efficiency of US Hospitals," International Journal of Health Care Finance and Economics, 6, 278-289.

Caves, Douglas W., Laurits R. Christenson, and W. Erwin Diewert. (1982) "The Economic Theory of Index Numbers and the Measurement of Input, Output and Productivity," Econometrica, 50, 1393-1414. 
Eggleston, Karen, Ling Li, Qingyue Meng, Magnus Lindelow, and Adam Wagstaff. (2008) "Health Service Delivery in China: A Literature Review," Health Economics, 17, $149-165$.

Emrouznejad, Ali and Gholam R Amin. (2008) "DEA Models for Ratio Data: Convexity Consideration," Applied Mathematical Modelling, 33, 486-498.

Färe, Rolf. (1988) Fundamentals of Production Theory. Springer-Verlag: New York.

Färe, Rolf, Shawna Grosskopf, Björn Lindgren, and Jean-Pierre Poullier. (1997) "Productivity Growth in Health-Care Delivery," Medical Care, 35, 354-366.

Färe, Rolf, Shawna Grosskopf, Björn Lindgren, and P. Roos. (1992) "Productivity Changes in Swedish Pharmacies 1980-1989: A Non-parametric Malmquist Approach," Journal of Productivity Analysis, 3, 85-101.

Färe, Rolf, Shawna Grosskopf, Mary Norris, and Zhongyang Zhang. (1994) "Productivity Growth, Technical Progress, and Efficiency Change in Industrialized Countries," American Economic Review, 84, 66-83.

Färe, Rolf, Shawna Grosskopf, and William L Weber. (1989) "Measuring School District Performance," Public Finance Quarterly, 17, 409-428.

Giokas, Dimitris I. (2001) “Greek Hospitals: How Well Their Resources Are Used,” Omega, 29, 73-83.

Giuffrida, Antonio. (1999) "Productivity and Efficiency Changes in Primary Care: A Malmquist Index Approach," Health Care Management Science, 2, 11-26.

Giuffrida, Antonio and Hugh Gravelle. (2001) "Measuring Performance in Primary Care: Econometric Analysis and DEA," Applied Economics, 33, 163-175.

$\mathrm{Gu}$, Edward and Jianjun Zhang. (2006) "Health Care Regime Change in Urban China: Unmanaged Marketization and Reluctant Privatization," Pacific Affairs, 79, 49-71.

Hollingsworth, Bruce. (2003) "Non-parametric and Parametric Applications Measuring Efficiency in Health Care," Health Care Management Science, 6, 203-218.

Hollingsworth, Bruce and Peter C. Smith. (2003) "Use of Ratios in Data Envelopment Analysis," Applied Economics Letters, 10, 733-735.

Hollingsworth, Bruce and John Wildman. (2003) "The Efficiency of Health Production: Reestimating the WHO Panel Data Using Parametric and Non-parametric Approaches to Provide Additional Information," Health Economics, 12, 493-504.

Hougaard, Jens Leth, Lars Peter Osterdal, and Yi Yu. (2008) "The Chinese Health Care System: Structure, Problems and Challenges," Discussion Paper, No. 08-01, Department of Economics, University of Copenhagen.

$\mathrm{Hu}$, Jin-Li and Yuan-Fu Huang. (2004) "Technical Efficiencies in Large Hospitals: A Managerial Perspective,” International Journal of Management, 21, 506-513.

Kirigia, Joses M., Ali Emrouzne, Luis G. Sambo, Nzoya Munguti, and Wilson Liambila. (2004) "Using Data Envelopment Analysis to Measure the Technical Efficiency of Public Health Centers in Kenya," Journal of Medical Systems, 28, 155-166.

Southern Regional Science Association 2010. 
Kontodimopoulos, Nick, Panagiotis Nanos, and Dimitris Niakas. (2006) "Balancing Efficiency of Health Services and Equity of Access in Remote Areas in Greece," Health Policy, 76, 49-57.

Liu, Xingzhu and Anne Mills. (2002) "Financing Reforms of Public Health Services in China: Lessons for Other Nations," Social Science \& Medicine, 54, 1691-1698.

Liu, Yuanli. (2004) "China's Public Health-Care System: Facing the Challenges," Bulletin of the World Health Organization, 82, 532-538.

Liu, Yangli, Peter Berman, Winnie Yip, Haocai Liang, Qingyue Meng, Jiangbin Qu, and Zhonghe Li. (2006) "Health Care in China: The Role of Non-government Providers," Health Policy, 77, 212-220.

Meng, Qingyue, Gang Cheng, Lynn Silver, Xiaojie Sun, Clas Rehnberg, and Göran Tomson. (2005) "The Impact of China's Retail Drug Price Control Policy on Hospital Expenditures: A Case Study in Two Shangdong Hospitals," Health Policy and Planning, 20, 185-196.

O’Neill, Liam, Marion Rauner, Kurt Heidenberger, and Markus Kraus. (2008) “A Cross-national Comparison and Taxonomy of DEA-based Hospital Efficiency Studies," Socio-Economic Planning Sciences, 42, 158-189.

Pilyavsk, Anatoly I., William E. Aaronson, Patrick M. Bernet, Michael D. Rosko, Vivian G. Valdmanis, and Mikhail V. Golubchikov. (2006) "East-West: Does It Make a Difference to Hospital Efficiencies in the Ukraine?," Health Economics, 15, 1173-1186.

Puig-Junoy, Jaume. (1998) "Measuring Health Production Performance in the OEDC," Applied Economics Letters, 85, 255-259.

Retzlaff-Roberts, Donna, Cyril F. Chang, and Rose M. Robin. (2004) "Technical Efficiency in the Use of Health Care Resources: A Comparison of OECD Countries," Health Policy, $69,55-72$.

Sahin, Ismet and Yasar A. Ozcan. (2000) "Public Sector Hospital Efficiency for Provincial Markets in Turkey," Journal of Medical Systems, 24, 307-320.

Shephard, Ronald W. (1970) The Theory of Cost and Production Functions. Princeton University Press: Princeton, NJ.

Tang, Shenglan and Qingyue Meng. (2004) "Introduction to the Urban Health System and Review of Reform Initiatives," Chapter 2 in Gerald Bloom and Shenglan Tang, eds, Health Care Transition in Urban China. Ashgate: Aldershot, England, pp. 13-38.

World Bank. (2005) The World Bank Report 2005, The World Bank: Washington, D.C.

Zavras, Athanasios, Georgios Tsakos, Charalabos Economou, and John Kyriopoulos. (2002) "Using DEA to Evaluate Efficiency and Formulate Policy Within a Greek National Primary Health Care Network," Journal of Medical Systems, 26, 285-292.

Zhang, Xiaobo and Ravi Kambur. (2005) "Spatial Inequality in Education and Health Care in China," China Economic Review, 16, 189-204.

Zhao, Y., Q. Wan, G. Gao, and L. Du. (2003) "Health Expenditures in China 2001," Chinese Journal of Health Economics, 22, 1-3. 